Original Research

\title{
Evolution of Radar and Lightning Variables in Convective Events in Barcelona and Surroundings for the Period 2006-2020
}

Tomeu Rigo ${ }^{1,+}{ }^{*}$, Sergio Castillo ${ }^{2,+}$

1. Servei Meteorològic de Catalunya, Berlin, 38-46 08029, Barcelona, Spain; E-Mail: tomeu.rigo@gencat.cat

2. Siemens Gamesa Renewable Energy, C/Ramírez de Arellano 37, 28043 Madrid, Spain; E-Mail: sergio.castillo@siemensgamesa.com

+ These authors contributed equally to this work.

* Correspondence: Tomeu Rigo; E-Mail: tomeu.rigo@gencat.cat

Academic Editor: Alfredo Moreira Caseiro Rocha

Special Issue: Remote Sensing on Climate Change

Adv Environ Eng Res

2021, volume 2, issue 2

doi:10.21926/aeer.2102004
Received: October 28, 2020

Accepted: March 24, 2021

Published: April 14, 2021

\begin{abstract}
The Metropolitan Area of Barcelona is a densely populated region in the North-East of the Iberian Peninsula. Infrastructures in this area play a significant role in the economy of this part of Europe. The combination of the Mediterranean Sea and the complex topography is responsible for the occurrence of severe weather events in this location and the surrounding areas. The use of remote sensing data in an hourly resolution allows the identification and characterization of those severe episodes, helping in determining the future trends of the adverse weather. This fact is crucial in the development of new engineering projects, as well as in the maintenance of the current ones. Weather radar and lightning observations have enabled the monitoring of an increase in severe weather occurrence and, in addition, the prime characteristics of the thunderstorms responsible for producing them. Deepening
\end{abstract}

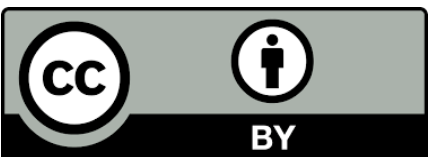

(C) 2021 by the author. This is an open access article distributed under the conditions of the Creative Commons by Attribution License, which permits unrestricted use, distribution, and reproduction in any medium or format, provided the original work is correctly cited. 
vertical developments, the presence of hail, and the decrease of the rainfall efficiency are some of the characteristics that must be taken into account in the near future.

\section{Keywords}

Lightning; weather radar; rainfall; echo top; variability; convection; Mediterranean

\section{Introduction}

Lightning is technically the process of spontaneous momentary high-current electrostatic discharge and usually occurs during thunderstorms $[1,2]$. The same definition of thunderstorm includes the occurrence of lightning in the clouds [3]. There are two primary categories of lightning $[1,2]$ : Intra-Cloud (IC) or discharges limited to the same cloud and not involving the earth's surface; and Cloud-to-Ground (CG), i.e., lightning discharges that bridge the gap between the cloud charge and the earth. Most of the lightning events (over 75\%) are IC; nevertheless, CG strongly affects human activities. Total Lightning (TL) is the sum of both types, IC and CG, in a thunderstorm. TL is a remarkable indicator of the variability of thunderstorms activity in a global [4] or local [5] context.

The relationship between radar data and lightning observations is a significant forecaster of various adverse weather types. Some instances are the nowcasting and surveillance of severe weather (large hail, strong convective winds, and/or tornadoes; see, for instance, [6-8]); the identification of fire initiations related to the thunderstorms [9]; or the characterization of the precipitation regime in a region [10-12]. The state-of-the-art analysis of the relationship between lightning and weather radar data presents two principal methodologies. The first one comprises the study of the thunderstorm's life cycle through certain parameters. On the other hand, the search for the correlation between radar and lightning fields can be identified.

The study of the thunderstorm's life cycle considers a set of cases, mainly severe, searching for the links between radar observations and electrical activity $[13,14]$. Few of the different radar parameters used are the surface reflectivity (adjusted to zero $\mathrm{km}$ height), the echo-top of $40 \mathrm{dBZ}$, and the Quantitative Precipitation Estimation (QPE) [15, 16], the echo top of 12 and $50 \mathrm{dBZ}$, and the Vertically Integrated Liquid (VIL) [17].

The second methodology involves the comparison of the QPE field from the weather radar using lightning flashes. This methodology derives an equation that provides the relationship between electrical activity and precipitation in a limited region. Certain studies illustrate results for different areas of China [10], the Western Mediterranean [18], tropical islands [11], and France [19]. The relationship between $C G$ lightning and surface precipitation during the warm season in six different regions (with areas of $10,000 \mathrm{~km} 2$ ) of the south-central United States was established earlier [20]. Since most of the operational networks only detect a small percentage of IC flashes due to the type of sensors used (Low Frequency, LF), many of these studies considered only the CG flashes. However, IC or TL data exhibit better correlations with the radar fields [21].

Influenced by the presence of the sea, the climate of most of the Mediterranean regions is characterized by sunny and warm days during a large part of the year; thus, being one of the 
principal centers of tourism across the globe. In the last part of summer and the early autumn, the convective activity acquires its peak in the western region of the Mediterranean Sea [22]. This enhances the risk during the period of increased activity in the touristic season by the combination of the complex topography and the proximity to the sea (see, for instance, [23, 24]). Catalonia forms part of the most affected regions, with a hike in the population of $10 \%$ due to tourism activity during summer [25], being positioned in a hot spot prone to suffer from floods and other catastrophic events. The efficient precipitation can also occur in shallow convection, but most damaging cases showed deep convective thunderstorms [24, 26].

The current work analyzes the evolution of convective thunderstorms in the Barcelona area, which is one of the principal regions of the Mediterranean and Europe in terms of population and economic aspects. The study has been conducted from a remote sensing point of view, considering the quality of lightning observations and radar data in the area of interest. The prime goal of the research is to investigate the trend of the number of cases in the region. This issue constitutes a crucial point in different scientific and engineering areas to understand the way this change can affect many human activities. Other secondary objectives included classifying the hourly activity based on the lightning and radar variables, characterizing each category according to the time distribution, and eventually, providing some key features regarding the different parameters for each of the classes. The manuscript includes the following sections: first, the presentation of the area of study, the data, and the methodology; the next sections are the results, followed by a discussion on the main points; and it concludes with the remarks.

\section{Area of Study, Data, and Methodology}

\subsection{Region of Study}

Catalonia is a region located at the North-East of the Iberian Peninsula (Figure 1, left), surrounded by Spain (west), France, the Pyrenees (north), and the Mediterranean Sea (east and south). The Metropolitan Area of Barcelona (MAB) is one of the densest areas of Europe (with more than $3,200,000$ people on a surface of $636 \mathrm{~km}^{2}$, which leads to a density of more than $5,000 \mathrm{hab} / \mathrm{km}^{2}$, the sixth-largest of the continent). This region is on the Central Coast of Catalonia (Figure 1, right). The selected area (ROI) in the research includes a part of the MAB $\left(202 \mathrm{~km}^{2}\right)$ and four natural elements that surround it: part of the Litoral range, the outfall of the Besòs and Llobregat rivers, and the Mediterranean Sea. 

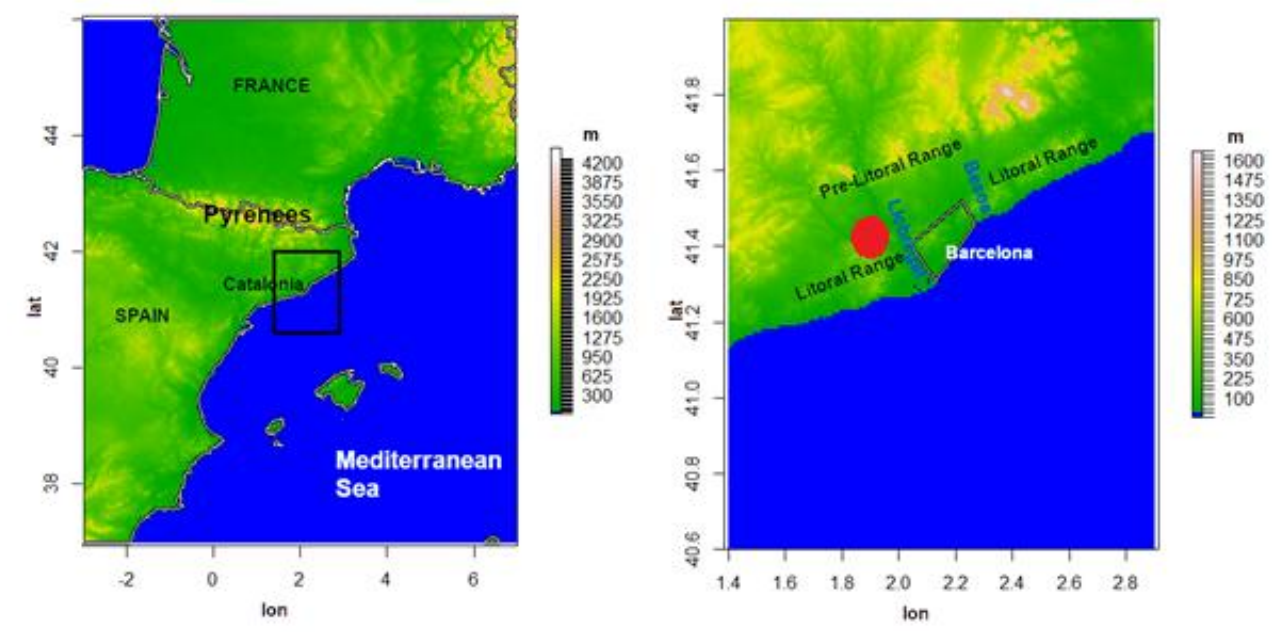

Figure 1 Left: Part of the Western Mediterranean basin. The rectangle represents the zoom area presented in the right image. Right: The area of study, marked by an irregular rectangle. The red dot marks the location of Vallirana Radar.

\subsection{Data Used}

\subsubsection{Radar Data}

A 3D composition for the whole territory of Catalonia has been produced by the Catalan Radar Network (hereafter XRAD) of the Weather Service of Catalonia (hereafter SMC), using the 4 C-Band Single polarization radars. The volumes are processed with a resolution of $6 \mathrm{~min}$, covering a large part of the lower and mid-atmospheric levels in the proximity of each one of the radars. More information about the network can be referred to elsewhere [27].

Four types of operative (this is, running in real-time) composite radar products have been used. The composites consider the maximum value over each point of the matrix of all the radars covering the pixel. The different products are:

- The hourly rainfall estimated by the XRAD, hereafter RN1 (Marshall-Palmer, $R=$ [ ( 10 $(\mathrm{dBZ} / 10)) / 200]^{5 / 8}$.

- The maximum hourly height where echoes are observed to be equal to or larger than 12 and $45 \mathrm{dBZ}$, reflectivity thresholds (hereafter TOP12 and TOP45).

- And finally, the maximum hourly Vertically Integrated Liquid (VIL) product, which indicates the total content of precipitable water in a vertical column.

\subsubsection{Lightning Data}

The Lightning Location System (LLS) of the SMC is composed of four detectors of Vaisala LS-8000 type. The network has the potential to detect flashes using VHF (Very High Frequency) and LF (Low Frequency) activity sources. A detailed report of the network configuration has given earlier [28]. The LLS has the particularity of detecting and allocating IC and CG flashes in a distinct way [29]. This characteristic leads to better results on the TL of thunderstorms characterization. The analysis of the 2013 campaign [30] established CG flash detection efficiency for the SMC-LLS around 80-85\%, 
and the estimated mean location accuracy is about $1 \mathrm{~km}$. The CG location is more precise rather than that of the IC. Radar, as well as lightning, have been cropped to the region of interest presented in the first subsection. The purpose is to avoid different anomalous signals observed, for instance, over the sea in front of the Barcelona coast, caused by anomalous propagation (weather radar) or external radio magnetic sources (lightning registers).

\subsection{Methodology}

The methodology constitutes the development of the following steps: The identification and characterization of the convective events over the ROI, the characterization of the radar variables for each period, and the time trend analysis of the variables. Each of the previous phases is elaborated in the following paragraphs.

\subsubsection{Identification and Characterization of the Convective Events Over the Region of Interest}

The first step was the detection of lightning data for each of the hourly periods from first January 2006 to first September 2020. Each period has been classified as a non-electrical activity (less than three flashes of any type); scarce intra-cloud activity (few IC flashes - less than 15 and quasi-null CG flashes, but more than $3 \mathrm{TL}$ ); reduced total lightning activity (more than 15 and less than $35 \mathrm{TL}$ flashes); moderate intra-cloud activity (more than 35 TL flashes, with few IC flashes - less than 175 and few CG flashes - less than 10); moderate total lightning activity (more than 175 TL and less than 275 TL flashes); high intra-cloud activity (more than 275 TL flashes, with a large number of IC flashes - more than 175 and less than 30 CG flashes); high total lightning activity (more than 275 TL flashes, with more than 30 CG flashes). These thresholds have been selected based on the authors' operational experience in the analysis of convection in the region.

\subsubsection{Characterization of the Radar Variables for Each Hourly Period}

Considering the volumetric radar composition of the XRAD, the $5^{\text {th }}, 50^{\text {th }}$, and $95^{\text {th }}$ percentiles of each data variable (TOP12 and TOP45, VIL and RN1) in the ROI box have been estimated. Extreme thresholds are selected to avoid the outliers associated with different radar errors (mainly ground and sea clutter and electromagnetic interferences). This allows estimating the general behavior of the thunderstorms producing lightning in the region.

\subsubsection{Time Trend Analysis of the Variables}

Using the Mann Kendall test, it has been possible to search for some signatures that could offer guidance on the future characteristics of the convective events in the ROI.

\subsubsection{Skill Scores Estimation}

Different parameters are computed for obtaining the accuracy of the relationship between the occurrence of lightning and the observation of rainfall structures in the radar imagery in the ROI. Considering the contingency table where $a=$ hits, $b=$ false alarms, $c=$ misses, and $d=$ correct negative, the selected skill scores used in the study were as follows [31]: 
POD (Probability of Detection): It is defined as the rate between the occasions when the forecast event occurred and the number of the observed cases. Zero value indicates a very bad forecast, and 1 is the perfect hit. Its equation is $P O D=a /(a+c)$

FAR (False Alarm Ratio): It corresponds to the fraction detected forecasts that turned out to be wrong. Zero value indicates the best forecast, and, on the contrary, 1 represents the worst scenario. It is calculated as FAR $=b /(a+b)$

HSS (Heidke Skill Score): It is a measurement of the improvement of the forecast over the standard. The range of the HSS is from the negative infinity to 1 . Negative values correspond to the better chance forecast; the 0 value represents no skill, while a perfect forecast occurs when HSS equal to 1 . The equation of this score is HSS $=2(a d-b c) /[(a+c)(c+d)+(a+b)(b+d)]$

\section{Results}

\subsection{Preliminary Description of the Lightning Data}

After the selection of those flashes included in the ROI, the number of IC, CG-(CN), and CG+ (CP) was computed for all the hourly periods. The distribution of the three types in a logarithmic form indicates some specificities of the lightning data in those hourly periods (Figure 2): Firstly, the number of cases with IC (a $0.9 \%$ of hourly periods) is larger than those where CG occur (only a $0.4 \%$ of the total). Besides, it is a highly possible case with 20 or more IC flashes, while CG-hardly exceeds the 7 per hour and CG+ rarely occurs in a number larger than 4 per hour. It is important to mention that CG+ are less usual than CG- (at a rate that is about 1/4), but they lead to more damage in cases like the setting of wildfires [9].
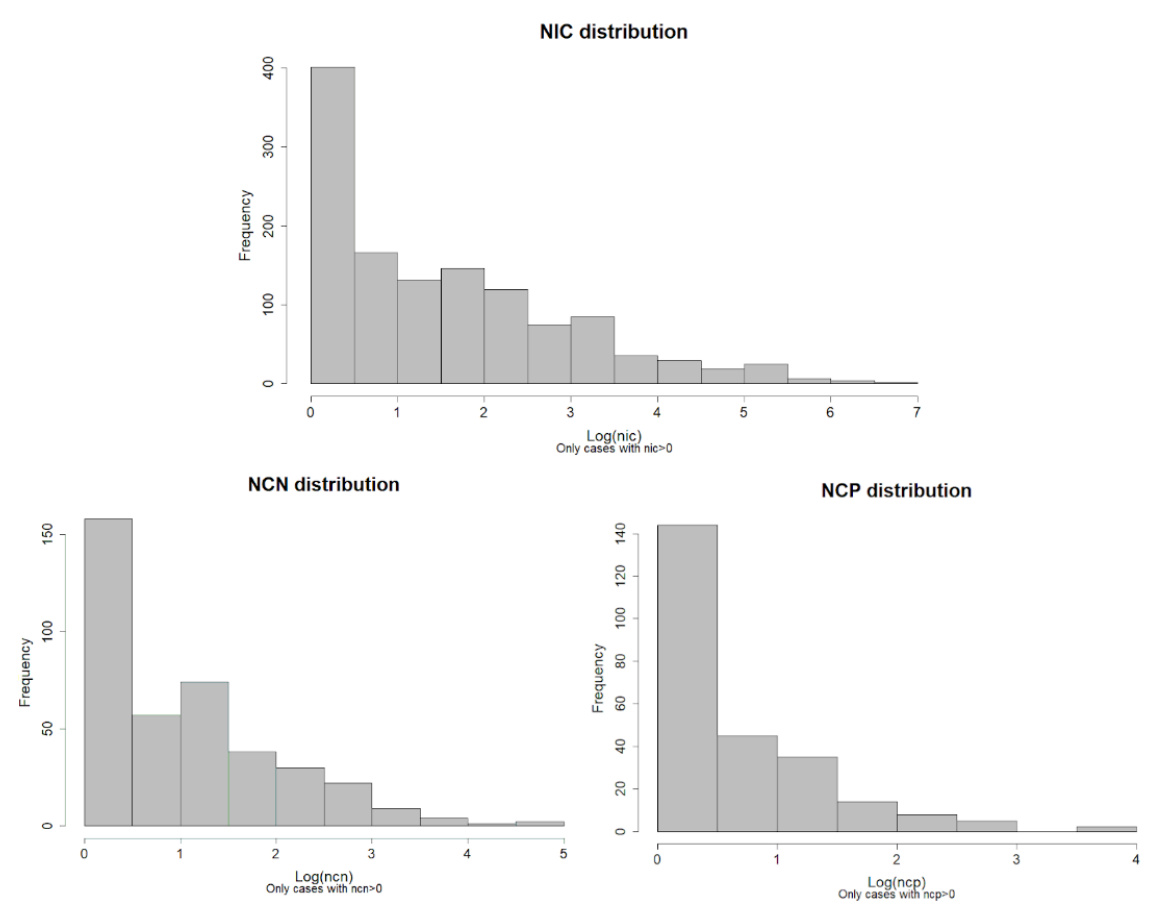

Figure 2 Total distribution of different types of flashes for the whole set of years (in hourly periods): Intra-clouds(top), negative cloud-to-ground (bottom left), positive cloud-to-ground (bottom right). 


\subsection{Identification and Characterization of the Convective Events}

From the previous considerations, the set of hourly periods is divided into seven categories, as illustrated in Section 2. Figure 3 represents the logarithmic distribution of the cases, indicating, as it was expected, most hours without lightning activity (99.4\%). Of those cases with flashes in the ROI, $50.8 \%$ of them represented only scarce IC, $13.7 \%$ scarce TL, $26.7 \%$ moderate IC, $5.5 \%$ moderate TL, $1.5 \%$ high IC, and $1.7 \%$ high TL.

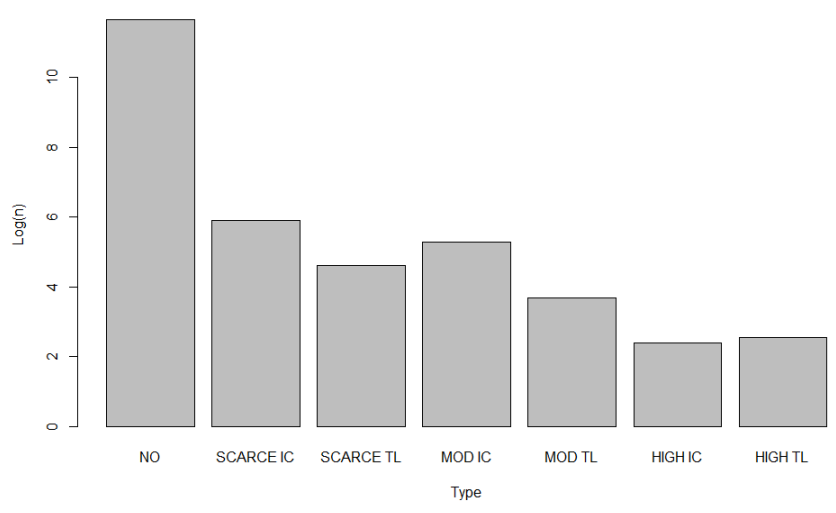

Figure 3 Distribution of hourly periods according to the IC and TL activity. From left to right: no activity at all, scarce IC activity, scarce TL activity (some CG detected), moderate IC activity (few or none CG detected), moderate TL (moderate IC and CG), high IC activity (with scarce or moderate CG activity), and high TL activity (both types of flashes).

Later, only 24 of the 114,984 h reported high activity, while it was moderate at $235 \mathrm{~h}$ with $729 \mathrm{~h}$ total registered electrical activity. This reduced number of cases with flashes in the ROI implies two primary facts: the statistical analysis seems less robust than for other meteorological phenomena and, on the other hand, its occurrence is usually associated with complications in the normal life of the citizens of $M A B$, constituting a matter of interest. Furthermore, the results could be exported to similar regions of the Mediterranean region, but also areas with a dense population and a corresponding occurrence of thunderstorms [32, 33].

\subsection{Radar Variables}

The four selected variables allow seeking information about the thunderstorm structures affecting the ROI: the TOP12 indicates the maximum height of the clouds as well as the TOP45 but for more intense parts of the thunderstorms. The VIL signifies a sort of probability of hail, and eventually, the RN1 illustrates the estimation of rainfall on the surface. It is important to mention that the values are not exact but help in understanding the behavior of the convective clouds.

Figure 4 summarizes the results, separating the cases with and without electrical activity for the period 2006-2020. The primary feature is that all the parameters indicate larger mean values in the cases with electrical activity occurrences: TOP12 reaches $15 \mathrm{~km}$ when flashes occur, while the opposite just arrives at $5 \mathrm{~km}$ height. Similar differences are reported for TOP 45, with 5.5 and 12.5 
$\mathrm{km}$, or RN1 $(0.5 \mathrm{~mm}$ vs. $21 \mathrm{~mm})$. The case of VIL is a bit different because the mean value is similar ( $1 \mathrm{~mm}$ in both cases), but while approaching percentile 80 , the "No-flashes" case remains invariable, while the "Flashes" drift to a value of $4 \mathrm{~mm}$.
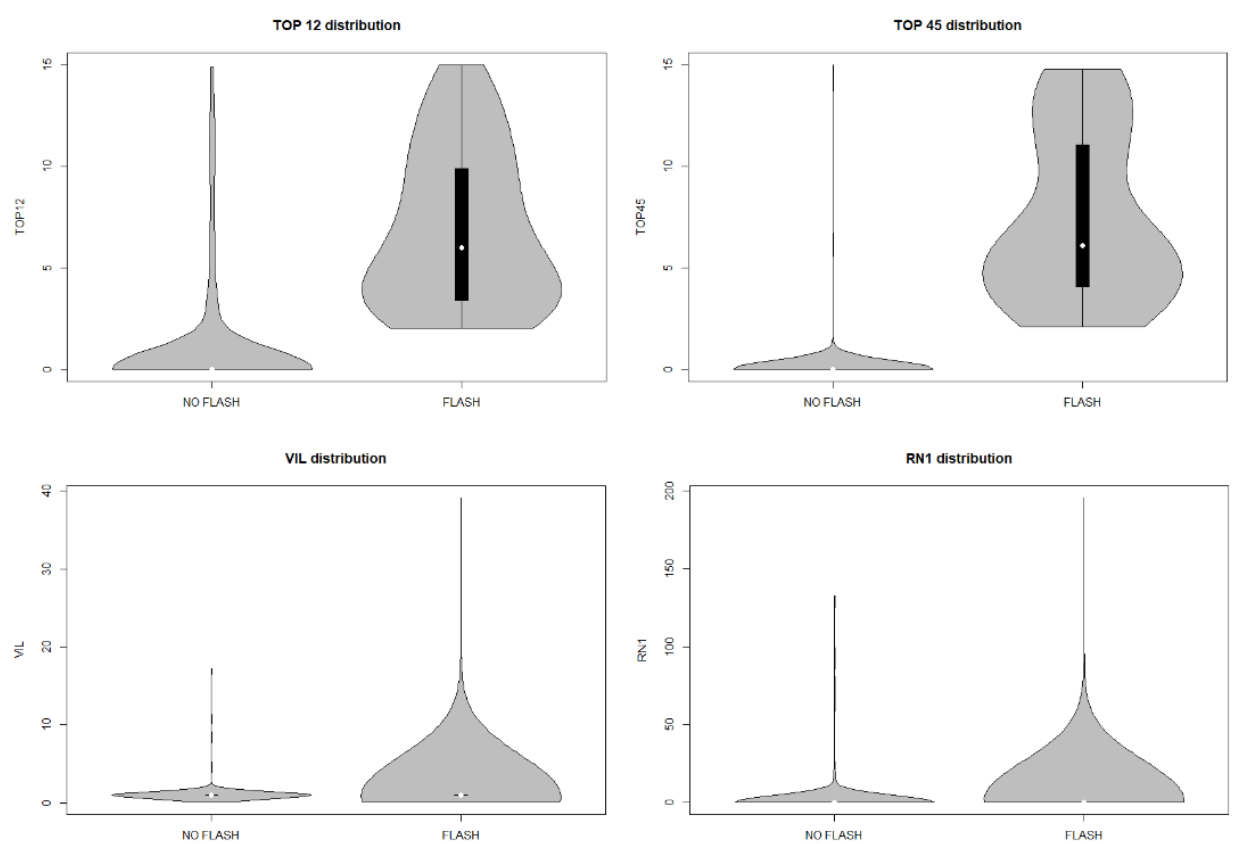

Figure 4 Violin plots of the different radar parameters: TOP12 $(\mathrm{km})$, TOP45 $(\mathrm{km}), \mathrm{VIL}$ $(\mathrm{mm})$, and RN1 (mm) for the period 2006-2020, for the cases without (left) and with (right) flashes.

The previous experiments confirm that the occurrence of lightning activity is more strictly related to heavy-rainfall and/or hail-producing well-developed clouds. There are certain cases ( $4 \%$ of the total hourly periods) without flashes where small hail could be observed (VIL>1 mm), while the percentage of hail possible cases is $37 \%$. Regarding heavy rainfalls (hourly rainfall exceeding $20 \mathrm{~mm}$ ), the percentages are $6.7 \%$ in episodes without lightning activity and $47.1 \%$ in case of lightning. Further, it is possible to have hail and/or heavy rainfall without lightning activity (probably associated with cases of warm rain, [24, 26, 34]), and not all lightning cases lead to hail and/or heavy rainfall.

\subsection{Trend of Different Parameters}

Moving to the main objective of this research, the evolution of convective episodes in the last years, Figure 5 reveals some crucial aspects about the behavior of lightning activity in the ROI: the first one, appreciable in all the types (from scarce IC to high $\mathrm{TL}$ ), is the large variability in the annual number of cases. In this regard, all the categories highlight the years with large activity as compared to others with null or few cases. The secondary point is the variation in behavior of all the six categories, with an unclear pattern of trending. In the process of clearly identifying the possible evolution of the whole set of electrical hourly periods, Figure 6 combines all of them in a similar way as Figure 5. 

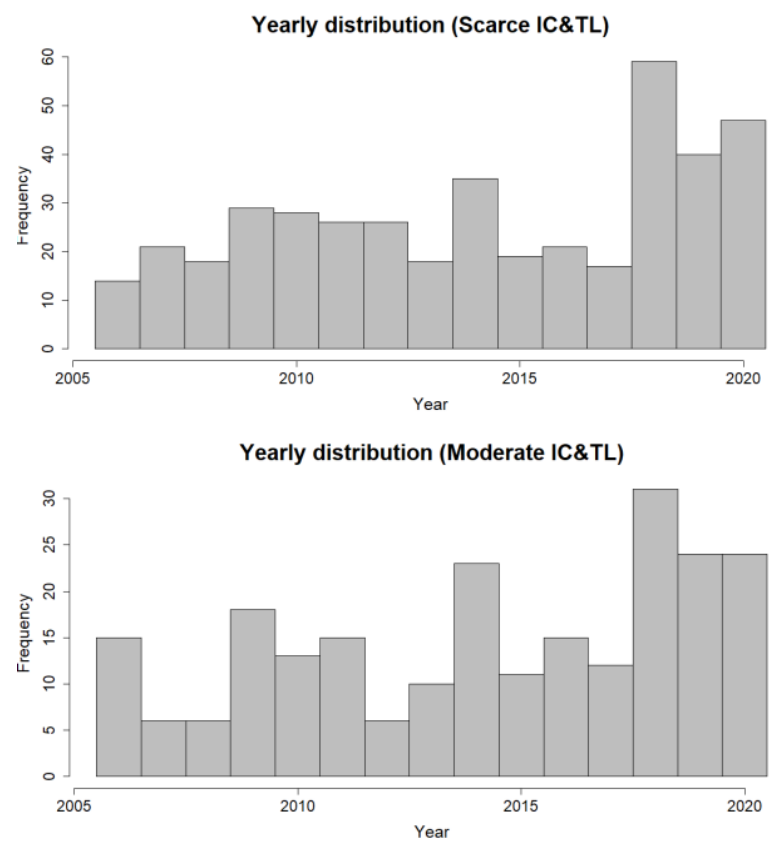

Yearly distribution (High IC\&TL)

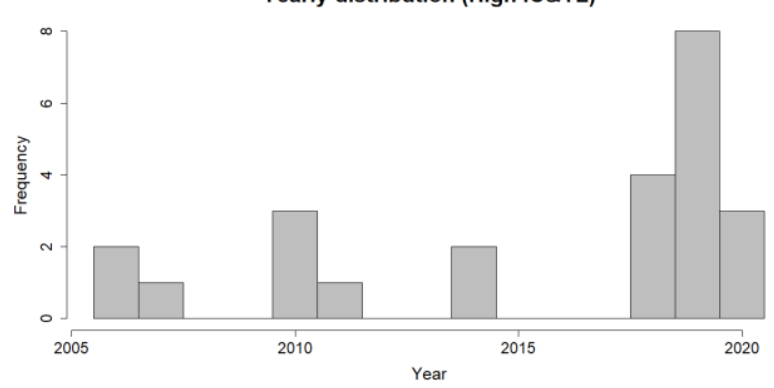

Figure 5 Annual distribution for the 3 categories (from top to bottom: Scarce, moderate, and high, merging IC and TL).

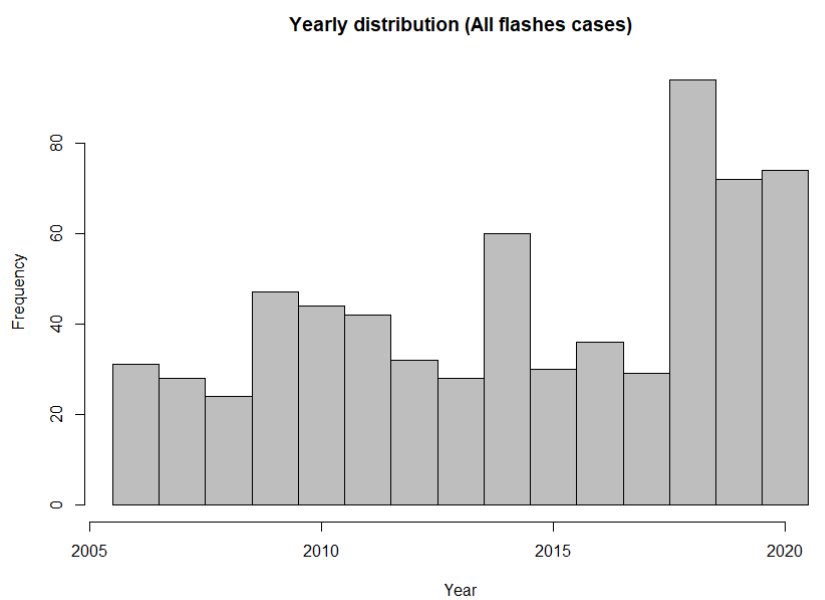

Figure 6 The annual sum of the hourly periods with lightning events grouping all the categories.

Figure 6 confirms the annual variability of the number of hourly convective periods in the ROI, but the discrepancies are less visible and allow detecting a trend of hike in the number of cases in 
the last years, in a similar manner as Figure 5, although the short period is probably not enough for representing a climatic perspective. Considering that the mean is $43 \mathrm{~h}$ per year, the last three years have evidently exceeded this threshold. On the contrary, from the first 11 years (2006-2020) only 2 of them reported values over 43 cases. To evaluate the rising trend of stormy activity, the MannKendall test is done for all-flash cases as well as scarce, moderate, and high TL categories (Table 1).

Table 1 Mann-Kendall test for all-flash cases and scarce, moderate, and high TL activity.

* confidence level of $90 \%$; $* *$ confidence level of $95 \%$.

\begin{tabular}{lll}
\hline Lightning Activity & Sen's slope & p-value \\
\hline All flash-cases & 2.4 & $0.0828^{*}$ \\
High activity & 0 & 0.4612 \\
Moderate activity & 1 & $0.0359^{* *}$ \\
Scarce activity & 1.64 & 0.1012 \\
\hline
\end{tabular}

A positive Sen's slope has been observed in almost all the categories, which is statistically significant at $95 \%$ of a confidence level for moderate activity. All flash-cases category represents a stronger positive Sen's slope at $90 \%$ confidence level.

The analysis of radar parameters aims to understand this variation in behavior. The study comprises the estimation of percentile 95 of different variables in the ROI for each hourly period with the electrical activity of any category besides, for those periods without flashes occurring more or equal than $3 \mathrm{~h}$ before and less or equal than $3 \mathrm{~h}$ after a lightning interval. This threshold is chosen based on the authors' experiences. Apparently, the analysis considers 467 flash hourly periods and 1381 non-flash periods. The annual results for each type (non-flash and flash) are highlighted in Figure 7. The results failed to draw a conclusion for any of the variables, but one interesting point has been discovered which could lead to further research in this domain: Table 2 represents the thresholds that have provided better correlations between non-flashes and flashes events, according to the skill scores indices and, also, from the Figure 4 violin plots. These thresholds behave as indicators of electrical activity, considering that the skill scores obtained are not optimal: POD of 0.49 , FAR of 0.29 , and HSS of 0.47 . This indicates that most of the non-flashes periods have been well identified, but a considerable number of flashes periods occurred with lower values. 

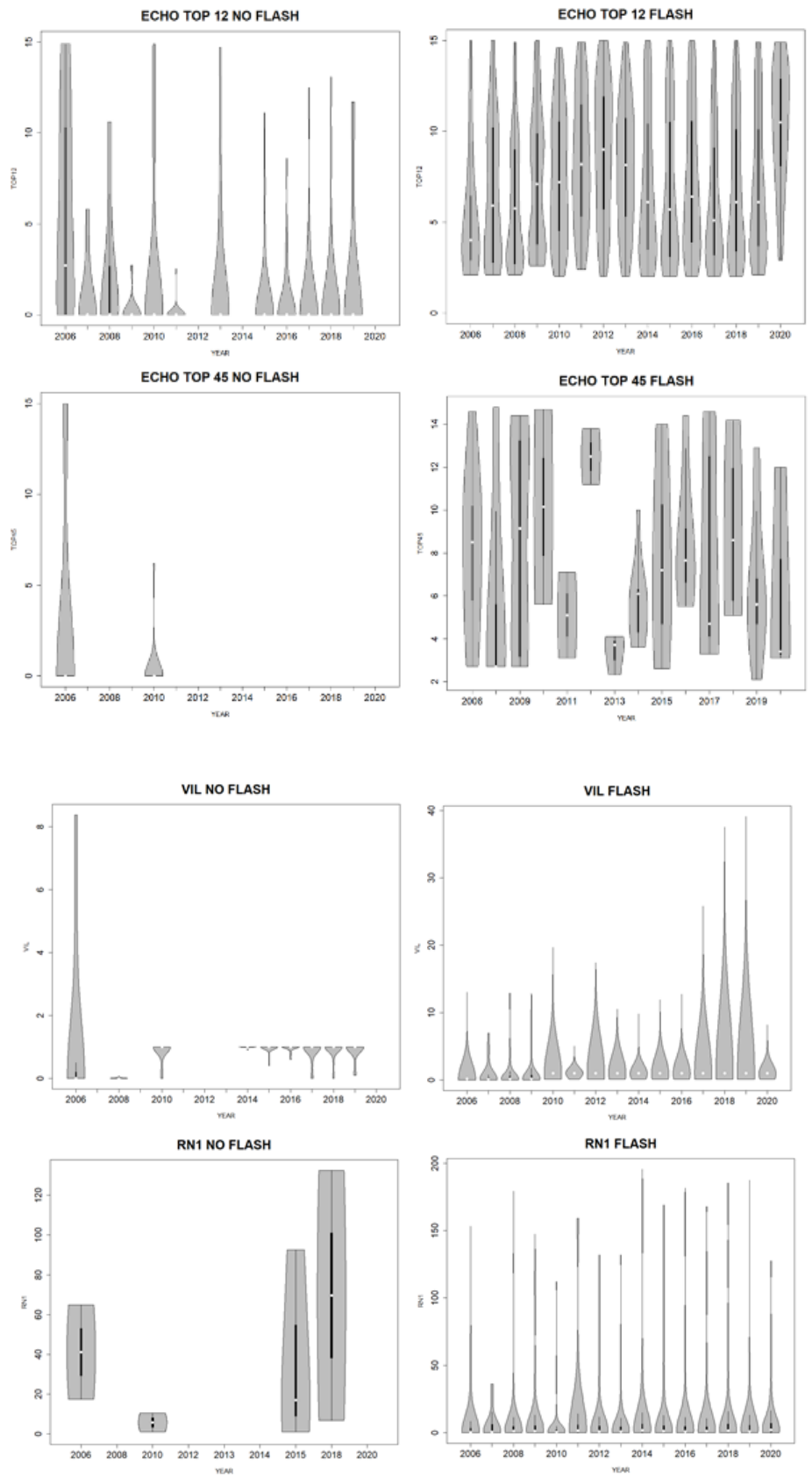

Figure 7 Annual radar parameters (from top to bottom: TOP12, TOP45, VIL, and RN1) evolution and distribution for the period 2006-2020. No flash cases in the left column and flashes cases in the right column.

Table 2 Threshold values for the different radar parameters that conclusively discriminate between flash events and non-flash events.

\begin{tabular}{ll}
\hline Variable & Threshold \\
\hline TOP12 $(\mathrm{km})$ & $\mathbf{7 . 5}$ \\
TOP45 $(\mathrm{km})$ & 4 \\
RN1 $(\mathrm{mm})$ & 15 \\
VIL $(\mathrm{mm})$ & $\mathbf{2}$ \\
\hline
\end{tabular}


On the other hand, Figure 7 illustrates the evolution of different radar parameters during the period of analysis. Flash episodes and non-flash intervals have been distinguished by figuring out the differences between them. The increase in P50 thresholds can be observed in the hours with lightning activity, which is stronger in RN1 and VIL.

Comparison of the real number of flash hourly periods per year with the estimations from the different radar parameters is mentioned in Figure 8. Though none of the parameters can conclude the ground truth values, all of them report the increasing trend of cases. Furthermore, the three peaks (2009, 2014, and 2018) have also been well-reproduced by the radar parameters. A consequence of these results is that all the radar variables have increased their values gradually in the last years, except in the case of RN1. This fact could imply more severe weather events in thunderstorms with less rainfall efficiency. On the contrary, it seems that clouds producing heavy rainfall without lightning activity (warm rain cases) have increased their efficiency in the last five years.

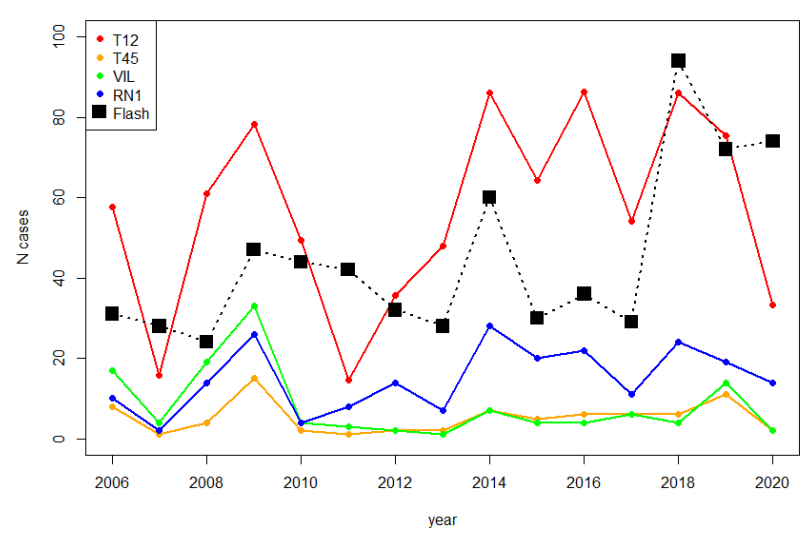

Figure 8 Real evolution of annual flash cases (black dots and lines) compared with the estimation of different radar parameters (TOP 12 in red, TOP45 in orange, VIL in green, and RN1 in blue).

\section{Discussion}

According to an earlier study [35], severe weather conditions occur when a combination of synoptic (atmospheric buoyancy and vertical wind shear) and mesoscale or local-scale (lifting mechanism) factors is noticed. Following this argument, there are two primary ways of affectation by severe weather over a region: thunderstorms developed over or close to the ROI (that is, the lifting mechanism is focused near the ROI), or, on the other hand, convective cells being born far of the ROI (because the atmospheric conditions help the propagation and maintenance of the severe conditions of a thunderstorm). In the first case, it implies that the atmospheric conditions must be favorable in the air-mass affecting the ROI. In the latter case, the structures developed at a certain distance relocate to the ROI, probably pushed by mid-high atmospheric winds [36]. This case implies that the affected area will be larger, but, on the contrary, the damages will probably be lower. However, there are a few cases where damages are serious and affecting areas are larger [37]. In 
both cases, the lightning activity, and particularly the IC one, is a good indicator of the occurrence, diagnosis, and warning of the severe thunderstorm activity [7, 38]. For this reason, the analysis of electrical occurrence in a region can furnish valuable information about the probability of severe weather, as has been analyzed in the current study. Besides, an earlier study [5] demonstrated the rich relationship between the height of the thunderstorm and the iso zero level. In this sense, the analysis of an earlier study [39] represented that for a close region (Southern France), the iso zero level has risen in the last couple of years, and it is expected that it will increase the annual mean value in the next decades. The authors reported that this point is related to the increase of severe weather phenomena (e.g., large hail).

The direct effects of the lightning are related to CG flashes, but the occurrence of IC implies direct convection. In most cases, the damages produced by thunderstorms can be a consequence of other phenomena: heavy rainfall, hail, straight winds, or tornadoes [1]. It is hence important to consider not only those periods with CG flashes but all those with the occurrence of any types of electrical activity. Effects of severe weather are crucial in the life of inhabitants of densely populated regions but also constitute a large problem owing to the damages caused to the different types of infrastructures, from private buildings to large wind-farms or agricultural exploitations [40-43]. Later, the increasing number of events constitutes a problem in the city engineering because of the wearing of the infrastructures, when they are more exposed to adverse weather phenomena (large hail, strong winds, and heavy rainfall). In any of the cases, the short period of data constitutes the larger difficulty at the time of verifying the results, in regards to such complicated issues, which is severe weather (see, for instance, [44]). For this reason, the authors encourage extensive research combining the largest types of sources available in the case they are comparable.

Severe weather phenomena in Catalonia are mainly hail and straight-winds (mainly associated with a downburst), as illustrated earlier $[6,45]$. However, tornadoes are also possible in the vicinity or over of the ROI, as suggested earlier [46] for a case that affected the International Airport of Barcelona, with a tornado outbreak streaking the buildings, some planes, and other infrastructures of the airport. This is not an isolated case in the region [47], but it is also observed that in some cases, waterspouts and tornadoes do not link directly with severe thunderstorms [48] but with other cloud dynamics. In any case, severe thunderstorms have been recorded as one of the most dangerous impact phenomena over Catalan society.

The importance of certain infrastructures, such as the airport, harbor, railways, or highways, combined with the high population density, gives a large value to those analysis focused on understanding the past, current, and future stages in regions with similar conditions as mentioned here [23], others parts of Catalonia [24], or other regions of the Mediterranean [49]. In general, the results demonstrate significant similarities for all the areas and types of phenomena, leading to the perception of the increasingly severe weather activity in the Mediterranean region.

Eventually, it is worthy to note that the results obtained in this research coincide with other works $[24,39]$. All the studies suggest that convective events producing severe weather phenomena will increase in the Mediterranean Area in the future. This point results in severity for policymakers at the time of searching for solutions for minimizing their effects. These solutions are more pivotal in populated areas such as the ones studied here. In this sense, the nowcasting limitations on these cases justify the use of remote sensing data (chiefly weather radar and lightning sensors). These 
tools could help in identifying some key elements such as lightning jump or splitting thunderstorms, which can provide a very valuable time for reducing the damages. In any case, similar to the work done in the United States [50], with public warning systems or educational courses, results are obliged to seek optimal results.

\section{Conclusions}

This paper represents a research analysis of remote sensing data (lightning and weather radar) as an attempt to resolve the issue of the increase in severe weather and thunderstorm activity in a very small region of the Mediterranean Iberian Peninsula coast. The main interest of the area is the high-density population and the large number of potentials affecting the infrastructures. The results support new developments from an engineering point of view. Taking benefit from severe weather (hail, straight winds, and/or tornadoes) is well related to total lightning data; the analysis focuses on the identification of hourly periods with electrical activity for the period 2006-2020. Answering the main question, it has reported an increment in the number of hourly electrical activity periods per year, particularly during the last couple of years. However, based on the climatic conditions, the period of the analysis is not long enough for providing a conclusive result, but it furnishes a good trend of the future scenario in the region. A positive tendency has been confirmed by the aforementioned Mann-Kendall test.

The comparison with radar data has allowed identifying the thresholds for various products (echo tops, VIL, and hourly rainfall estimation), which permits discriminating between lightning and nonlightning activity over the region of analysis. The period of analysis has been reduced to have a homogenous radar data series. Although the skill scores of the number of annual events are not idealistic (with a considerable underestimation), the radar thresholds indicated the same trends as the lightning registers.

Another important result obtained from the radar analysis is the reduction of the rainfall estimation for the flash-producing hours. On the contrary, VIL values have increased in the last few years. This should imply that severe thunderstorms include more hail events, reducing the efficiency of the rainfall.

Future research must include various points such as a comparison with ground observations (for instance, automatic weather stations or spotter registers), the analysis of thermodynamic conditions, and extending the area of study to a larger region.

\section{Acknowledgements}

The authors want to thank the Meteorological Service of Catalonia for the data provided.

\section{Author Contributions}

The authors have contributed equally to the design, research and writing of the manuscript.

\section{Competing Interests}

The authors have declared that no competing interests exist. 


\section{References}

1. Dwyer JR, Uman MA. The physics of lightning. Phys Rep. 2014; 534: 147-241.

2. Akinyemi ML, Boyo $A O$, Emetere $M E$, Usikalu MR, Olawole FO. Lightning a fundamental of atmospheric electricity. IERI Procedia. 2014; 9: 47-52.

3. Panofsky HA. Large-scale vertical velocity and divergence. In: Compendium of Meteorology. Boston, MA: American Meteorological Society; 1951. pp.639-646.

4. Williams E, Rothkin K, Stevenson D, Boccippio D. Global lightning variations caused by changes in thunderstorm flash rate and by changes in the number of thunderstorms. J Appl Meteorol. 2000; 39: 2223-2230.

5. Salvador A, Pineda N, Montanyà J, Solà G. Seasonal variations on the conditions required for the lightning production. Atmos Res. 2020; 243: 104981.

6. Farnell C, Rigo T, Pineda N. Lightning jump as a nowcast predictor: Application to severe weather events in Catalonia. Atmos Res. 2017; 183: 130-141.

7. Metzger E, Nuss WA. The relationship between total cloud lightning behavior and radar-derived thunderstorm structure. Weather Forecast. 2013; 28: 237-253.

8. Schultz CJ, Carey LD, Schultz EV, Blakeslee RJ. Insight into the kinematic and microphysical processes that control lightning jumps. Weather Forecast. 2015; 30: 1591-1621.

9. Pineda N, Rigo T. The rainfall factor in lightning-ignited wildfires in Catalonia. Agric For Meteorol. 2017; 239: 249-263.

10. Zhou Y, Qie X, Soula S. A study of the relationship between cloud-to-ground lightning and precipitation in the convective weather system in China. Ann Geophys. 2002; 20: 107-113.

11. Carey LD, Rutledge SA. The relationship between precipitation and lightning in tropical island convection: A C-band polarimetric radar study. Mon Weather Rev. 2000; 128: 2687-2710.

12. Soula S, Chauzy S. Some aspects of the correlation between lightning and rain activities in thunderstorms. Atmos Res. 2001; 56: 355-373.

13. Rigo T, Pineda N, Bech J. Analysis of warm season thunderstorms using an object-oriented tracking method based on radar and total lightning data. Nat Hazards Earth Syst Sci. 2010; 10: 1881-1893.

14. Williams E, Boldi B, Matlin A, Weber M, Hodanish S, Sharp D, et al. The behavior of total lightning activity in severe Florida thunderstorms. Atmos Res. 1999; 51: 245-265.

15. Bech J, Pineda N, Rigo T, Aran M. Remote sensing analysis of a Mediterranean thundersnow and low-altitude heavy snowfall event. Atmos Res. 2013; 123: 305-322.

16. Bech J, Arús J, Castán S, Pineda N, Rigo T, Montanyà J, et al. A study of the 21 March 2012 tornadic quasi linear convective system in Catalonia. Atmos Res. 2015; 158: 192-209.

17. Pineda N, Rigo T, Montanyà J, van der Velde OA. Charge structure analysis of a severe hailstorm with predominantly positive cloud-to-ground lightning. Atmos Res. 2016; 178: 31-44.

18. Pineda N, Rigo T, Bech J, Soler X. Lightning and precipitation relationship in summer thunderstorms: Case studies in the North Western Mediterranean region. Atmos Res. 2007; 85: 159-170.

19. Chèze JL, Sauvageot H. Area-average rainfall and lightning activity. J Geophys Res Atmos. 1997; 102: 1707-1715.

20. Sheridan SC, Griffiths JF, Orville RE. Warm season cloud-to-ground lightning-precipitation relationships in the south-central United States. Weather Forecast. 1997; 12: 449-458. 
21. Darden CB, Nadler DJ, Carcione BC, Blakeslee RJ, Stano GT, Buechler DE. Utilizing total lightning information to diagnose convective trends. Bull Am Meteorol Soc. 2010; 91: 167-176.

22. Ducrocq V, Braud I, Davolio S, Ferretti R, Flamant C, Jansa A, et al. HyMeX-SOP1: The field campaign dedicated to heavy precipitation and flash flooding in the northwestern Mediterranean. Bull Am Meteorol Soc. 2014; 95: 1083-1100.

23. Cortès $M$, Llasat $M C$, Gilabert J, Llasat-Botija $M$, Turco $M$, Marcos $R$, et al. Towards a better understanding of the evolution of the flood risk in Mediterranean urban areas: The case of Barcelona. Nat Hazards. 2018; 93: 39-60.

24. del Moral A, del Carmen Llasat M, Rigo T. Connecting flash flood events with radar-derived convective storm characteristics on the northwestern Mediterranean coast: Knowing the present for better future scenarios adaptation. Atmos Res. 2020; 238: 104863.

25. Llasat MC, Llasat-Botija M, Rodriguez A, Lindbergh S. Flash floods in Catalonia: A recurrent situation. Adv Geosci. 2010; 26: 105-111.

26. Ballart D, Figuerola F, Aran M, Rigo T. Analysis of warm convective rain events in Catalonia. Proceedings of the 11th Plinius Conference on Mediterranean Storms; 2009 September 7th10th; Barcelona, Spain. Göttingen: Copernicus Meetings.

27. Altube $\mathrm{P}, \mathrm{Bech} \mathrm{J}$, Argemí O, Rigo T. Quality control of antenna alignment and receiver calibration using the sun: Adaptation to midrange weather radar observations at low elevation angles. J Atmos Ocean Technol. 2015; 32: 927-942.

28. Pineda N, Montanyà J. Lightning detection in Spain: The particular case of Catalonia. In: Lightning: Principles, Instruments and Applications. Dordrecht: Springer; 2009. pp.161-185.

29. RIGO T, PINEDA N. Inferring the severity of a multicell thunderstorm evolving to supercell, by means of radar and total lightning. Electron J Severe Storms Meteorol. 2016; 11: 1-27.

30. Montanyà J. Annual report on the performance of the lightning location system operated by the meteorological service of Catalonia. Int Tech Rep. 2014.

31. Wilks DS. Statistical methods in the atmospheric sciences. 3rd ed. Cambridge, MA: Academic press; 2011. pp.704.

32. Bonelli P, Marcacci P, Bertolotti E, Collino E, Stella G. Nowcasting and assessing thunderstorm risk on the Lombardy region (Italy). Atmos Res. 2011; 100: 503-510.

33. Sioutas MV. A tornado and waterspout climatology for Greece. Atmos Res. 2011; 100: 344-356.

34. Farnell C, Rigo T. The lightning jump algorithm for nowcasting convective rainfall in Catalonia. Atmosphere. 2020; 11: 397.

35. Moller AR, Doswell III CA, Foster MP, Woodall GR. The operational recognition of supercell thunderstorm environments and storm structures. Weather Forecast. 1994; 9: 327-347.

36. Rotunno R, Klemp J. On the rotation and propagation of simulated supercell thunderstorms. J Atmos Sci. 1985; 42: 271-292.

37. Johns RH, Hirt WD. Derechos: Widespread convectively induced windstorms. Weather Forecast. 1987; 2: 32-49.

38. Schultz CJ, Petersen WA, Carey LD. Preliminary development and evaluation of lightning jump algorithms for the real-time detection of severe weather. J Appl Meteorol Climatol. 2009; 48: 2543-2563.

39. Dessens J, Berthet C, Sanchez JL. Change in hailstone size distributions with an increase in the melting level height. Atmos Res. 2015; 158: 245-253.

40. Duranona V, Marchesoni E, Sallés R. A first characterization of high winds that affect the energy 
distribution system of Uruguay and their related effects. J Wind Eng Ind Aerodyn. 2019; 184: 128-138.

41. Hanak T, Korytarova J. Risk zoning in the context of insurance: Comparison of flood, snow load, windstorm and hailstorm. J Appl Eng Sci. 2014; 12: 137-144.

42. Crichton D, Nicol F, Roaf S. Adapting buildings and cities for climate change: A 21st Century survival guide. 2nd ed. New York: Routledge; 2009.

43. Rigo T, Farnell C. Using maximum vertical integrated liquid (VIL) maps for identifying hailaffected areas: An operative application for agricultural purposes. J Mediterranean Meteorol Climatol. 2019; 16: 15-24.

44. Robinson ED, Trapp RJ, Baldwin ME. The geospatial and temporal distributions of severe thunderstorms from high-resolution dynamical downscaling. J Appl Meteorol Climatol. 2013; 52: 2147-2161.

45. Farnell C, Rigo T. The lightning jump, the 2018 "Picking up Hailstones" campaign and a climatological analysis for Catalonia for the 2006-2018 Period. Tethys. 2020; 17: 10-20.

46. Bech J, Pascual R, Rigo T, Pineda N, López JM, Arús J, et al. An observational study of the 7 September 2005 Barcelona tornado outbreak. Nat Hazards Earth Syst Sci. 2007; 7: 129-139.

47. Gayá M, Llasat MC, Arús J. Tornadoes and waterspouts in Catalonia (1950-2009). Nat Hazards Earth Syst Sci. 2011; 11: 1875-1883.

48. Rodríguez $\mathrm{O}$, Bech J. Sounding-derived parameters associated with tornadic storms in Catalonia. Int J Climatol. 2018; 38: 2400-2414.

49. Michaelides S, Karacostas T, Sánchez JL, Retalis A, Pytharoulis I, Homar V, et al. Reviews and perspectives of high impact atmospheric processes in the Mediterranean. Atmos Res. 2018; 208: 4-44.

50. Drost R, Casteel M, Libarkin J, Thomas S, Meister M. Severe weather warning communication: Factors impacting audience attention and retention of information during tornado warnings. Weather Clim Soc. 2016; 8: 361-372.

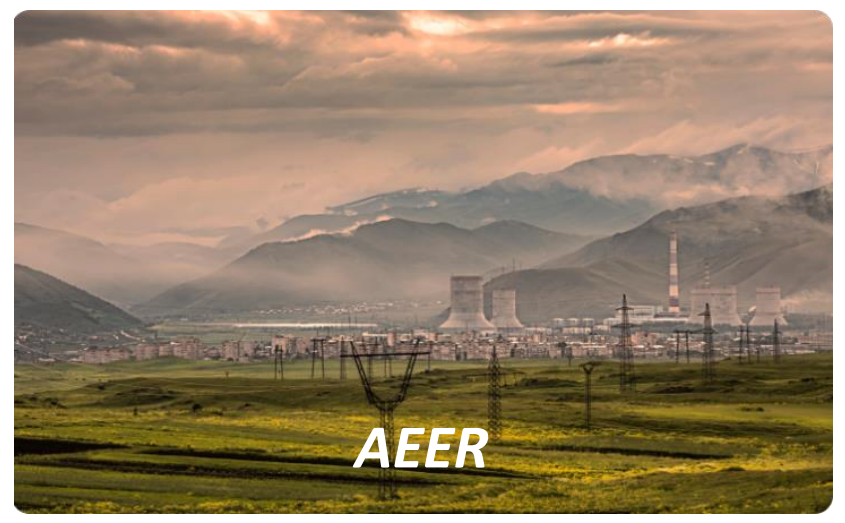

Enjoy AEER by:

1. Submitting a manuscript

2. Joining in volunteer reviewer bank

3. Joining Editorial Board

4. Guest editing a special issue

For more details, please visit:

http://www.lidsen.com/journals/aeer 